\title{
Effect of unaccustomed eccentric exercise on proprioception of the knee in weight and non-weight bearing tasks
}

\author{
Carolina Vila-Chã ${ }^{\mathrm{a}}$, Simone Riis ${ }^{\mathrm{a}}$, Ditte Lund ${ }^{\mathrm{a}}$, Anders Møller ${ }^{\mathrm{a}}$, Dario Farina ${ }^{\mathrm{a}, \mathrm{b}}$, Deborah Falla ${ }^{\mathrm{a}, \mathrm{b}, *}$ \\ ${ }^{a}$ Centre for Sensory-Motor Interaction (SMI), Department of Health Science and Technology, Aalborg University, Fredrik Bajers Vej 7, D-3, DK-9220, Aalborg, Denmark \\ ${ }^{\mathrm{b}}$ Department of Neurorehabilitation Engineering, Bernstein Center for Computational Neuroscience, Georg-August University of Göttingen, Göttingen, Germany
}

\section{A R T I C L E I N F O}

\section{Article history:}

Received 2 July 2010

Received in revised form 14 September 2010

Accepted 1 October 2010

\section{Keywords:}

Proprioception

Quadriceps

Eccentric exercise

DOMS

\begin{abstract}
A B S T R A C T
The study investigates the effects of eccentric exercise of the quadriceps on proprioception of the knee in weight and non-weight bearing tasks. Proprioception of the exercised leg was assessed at $120^{\circ}$ and $150^{\circ}$ of knee extension in 15 healthy adults (age $25.0 \pm 3.6 \mathrm{yrs}$ ) before, immediately after, and $24 \mathrm{~h}$ following eccentric exercise of the quadriceps. Three tests of proprioception were performed: 1 . matching the position of the exercised leg (right leg) to the reference leg (left leg) in sitting (non-weight bearing matching task); 2 . repositioning the exercised leg after active movement in sitting (non-weight bearing repositioning task); 3. repositioning the exercised leg after active movement in standing (weight bearing task). Maximum knee extension force was reduced by $77.0 \pm 12.3 \%$ immediately after the exercise, and by $82.7 \pm 16.2 \% 24$ h post exercise, with respect to baseline $(P<0.001)$. The absolute error in the non-weight bearing matching task at $120^{\circ}$ of knee extension was greater immediately following eccentric exercise $(12.3 \pm 5.6, P<0.001)$ and $24 \mathrm{~h}$ after exercise $(8.1 \pm 4.5, P<0.05)$ compared to baseline $(5.8 \pm 2.7)$. Similarly, the absolute error in the non-weight bearing repositioning task at $120^{\circ}$ was greater both immediately $\left(5.9 \pm 3.1^{\circ}, P<0.01\right)$ and $24 \mathrm{~h}$ post exercise $\left(5.2 \pm 3.0^{\circ}, P<0.05\right)$ compared to baseline $\left(4.5 \pm 2.6^{\circ}\right)$. Therefore, in both non-weight bearing tasks, the subjects matched the position of their leg after eccentric exercise by adopting a more extended knee position of the exercised limb. Furthermore, the subjects showed higher variability in their performance immediately post exercise $(P<0.05$, compared to baseline) but not $24 \mathrm{~h}$ after. In contrast, eccentric exercise did not affect the repositioning errors in the weight bearing task. In conclusion, eccentric exercise of the quadriceps impairs proprioception of the knee both immediately after and $24 \mathrm{~h}$ post exercise, but only in non-weight bearing tasks.
\end{abstract}

(c) 2010 Elsevier Ltd. All rights reserved.

\section{Introduction}

Unaccustomed eccentric exercise typically leads to myofibrillar damage, disturbance of the extracellular matrix and an inflammatory reaction (Howell et al., 1993; Jones et al., 1987; Yu and Thornell, 2002). The sensation of pain and muscle stiffness normally begins several hours after unaccustomed eccentric exercise, reaches a peak 24-48 h after and may even persist for several days (Armstrong, 1984; Jones et al., 1987). This phenomenon - delayed-onset muscular soreness (DOMS) - is associated with prolonged muscle force loss, reduction of joint range of motion, a sensation of unsteady limbs and clumsiness in precision movements (Brockett et al., 1997; Howell et al., 1993; Paschalis et al., 2007; Proske et al., 2003; Saxton et al., 1995), and impaired proprioception (Proske and Allen, 2005).

Several studies have shown that immediately after either eccentric or concentric exercise, the size of errors observed during position- and force-matching tasks increases significantly (Walsh

\footnotetext{
* Corresponding author. Tel.: +45 994074 59; fax: +45 98154008 .

E-mail address: deborahf@hst.aau.dk (D. Falla).
}

et al., 2004; Allen and Proske, 2006; Givoni et al., 2007). Furthermore, these studies show that the degree of matching errors is associated with the degree of force reduction due to either muscle fatigue or DOMS (Walsh et al., 2004; Givoni et al., 2007). Although proprioception can be impaired following both eccentric and concentric exercise, it appears to be affected more following eccentric exercise (Walsh et al., 2004; Givoni et al., 2007). This is presumably due to the greater reduction in force following eccentric compared to concentric exercise (Walsh et al., 2004; Winter et al., 2005). After eccentric exercise, the impairment in force lasts for 24-48 h (Lephart and Fu, 2000; Proske and Morgan, 2001) and significant matching errors are still observed after $24 \mathrm{~h}$ (Givoni et al., 2007).

These observations contributed to the effort hypothesis, which suggests that the sense of effort or heaviness generated by central motor commands play an important role in joint position sense (for review see Proske and Gandevia, 2009). Since maximal force is reduced after exercise, the effort required to support the limb increases, altering the sense of effort (Walsh et al., 2006) resulting in reduced joint position accuracy. Nevertheless, the effort hypothesis has not been confirmed under all circumstances (Proske and 
Gandevia, 2009), indicating that other peripheral and/or central mechanisms contribute to impaired proprioception.

Impairment of proprioception may influence joint stability and has been associated with the occurrence of knee injuries in sports and exercise (Granata et al., 1999; Givoni et al., 2007; Kelly, 2008; Sanna and O'Conner, 2008). However, the majority of studies examining the effects of exercise on proprioception have examined the upper extremities in non-weight bearing positions (Walsh et al., 2004; Proske et al., 2004; Allen et al., 2007). Knowledge on the effect of exercise on proprioception in weight bearing positions is also needed since most knee injuries occur in weight bearing positions. For example, anterior cruciate ligament injuries commonly occur with change of direction in a weight bearing position with a fixed distal extremity (Kelly, 2008; Sanna and O'Conner, 2008).

This study examines the immediate and delayed effects of eccentric exercise on proprioception of the knee during weight and non-weight bearing tasks. It was hypothesized that proprioception would be less affected in weight bearing since proprioceptive feedback from other sources may compensate for the loss of proprioception induced by eccentric exercise.

\section{Materials and methods}

\subsection{Subjects}

Fifteen healthy volunteers participated in the experiment (9 men; age, mean $\pm S D, 25.0 \pm 3.6 \mathrm{yrs}$ ). To control for potential learning effects, an additional 10 healthy subjects were recruited as a control group ( 5 men; age, $22.0 \pm 0.8$ yrs). The participants were free of lower limb injuries. The study was conducted in accordance with the Declaration of Helsinki and approved by the Local Ethics Committee (N-20070019). Subjects provided informed written consent prior to participation in the study.

\subsection{Procedure}

Maximum voluntary knee extension force and proprioception of the right knee were tested at baseline, immediately following eccentric exercise, and $24 \mathrm{~h}$ after eccentric exercise. To confirm the presence of DOMS 24 h post exercise, participants marked their area of pain on a body chart and verbally rated their perceived pain on a scale from 0 ("no soreness") to 10 ("worst soreness imaginable"). The subjects were asked to rate the average pain intensity in the quadriceps during their regular activities of daily living (e.g. descending stairs) since their last visit to the laboratory (over the past $24 \mathrm{~h}$ ).

\subsubsection{Eccentric exercise}

The eccentric exercise protocol was performed in a KinCom dynamometer (Chattanooga Group Inc.). The subject sat comfortably on the adjustable chair of the KinCom with the hip in $90^{\circ}$ flexion. The chair position was modified until the knee axis of rotation (tibio-femoral joint) was aligned with the axis of rotation of the dynamometer's attachment arm. The subject was fixed with straps secured across the chest and hips. The right leg was secured in $90^{\circ}$ knee flexion to the attachment arm with a Velcro strap and an additional strap was placed over the subjects' thigh. Subjects performed 4 sets of 25 maximum voluntary eccentric knee extension contractions at a speed of $60^{\circ} / \mathrm{sec}$ between $170^{\circ}$ to $90^{\circ}$ of knee extension ( $180^{\circ}$ : full knee extension). A resting period of 3 min was given between each set of contractions. During the exercise, the subject was provided with visual feedback of force and was constantly encouraged to maintain maximal force for each repetition.

\subsubsection{Maximal voluntary contraction}

Maximal voluntary isometric contraction (MVC) force was measured for the knee extensors using the KinCom isokinetic Dynamometer. Visual feedback of torque was provided on a screen positioned in front of the subject. With the knee flexed to $90^{\circ}$, the subject was asked to perform three MVCs of 3-5 s duration, with 2 min of rest in between with verbal encouragement to exceed the previous force level. The reference MVC value corresponded to the maximal force exerted in the three trials.

\subsubsection{Proprioception tasks}

With the subjects blindfolded, proprioception of the right knee was assessed at $120^{\circ}$ and $150^{\circ}$ of knee extension in 3 tasks: 1 . Matching the position of the exercised leg (right leg) to the reference leg (left leg), which was held at the predetermined angles (non-weight bearing position matching task - $\mathrm{POS}_{\mathrm{N}-\mathrm{WB}}$ ); 2. Repositioning the exercised leg to the predetermined angles following active movement (non-weight bearing repositioning task - REPOS $_{\mathrm{N}-}$ ${ }_{\text {wB }}$ ); 3. Repositioning the exercised leg after active movement in a weight bearing position (weight bearing repositioning task - RE$\mathrm{POS}_{\mathrm{WB}}$ ). For the first two tasks, the subjects were seated in an elevated chair so that their legs were freely moving, whilst for the third task the subjects were standing (Fig. 1). To provide a measure of knee joint angle, an electro-goniometer (Biometrics Ltd) was attached to the subject's right knee. The output was calibrated for knee joint angle and recorded during the proprioception tasks.

For the $\mathrm{POS}_{\mathrm{N}-\mathrm{WB}}$ task, the left leg was positioned at an angle of $120^{\circ}$ or $150^{\circ}$ using a manual goniometer and the subjects were asked to move their right leg to match the position of the left leg as accurately as possible. For the $\operatorname{REPOS}_{\mathrm{N}-\mathrm{WB}}$, the right leg was
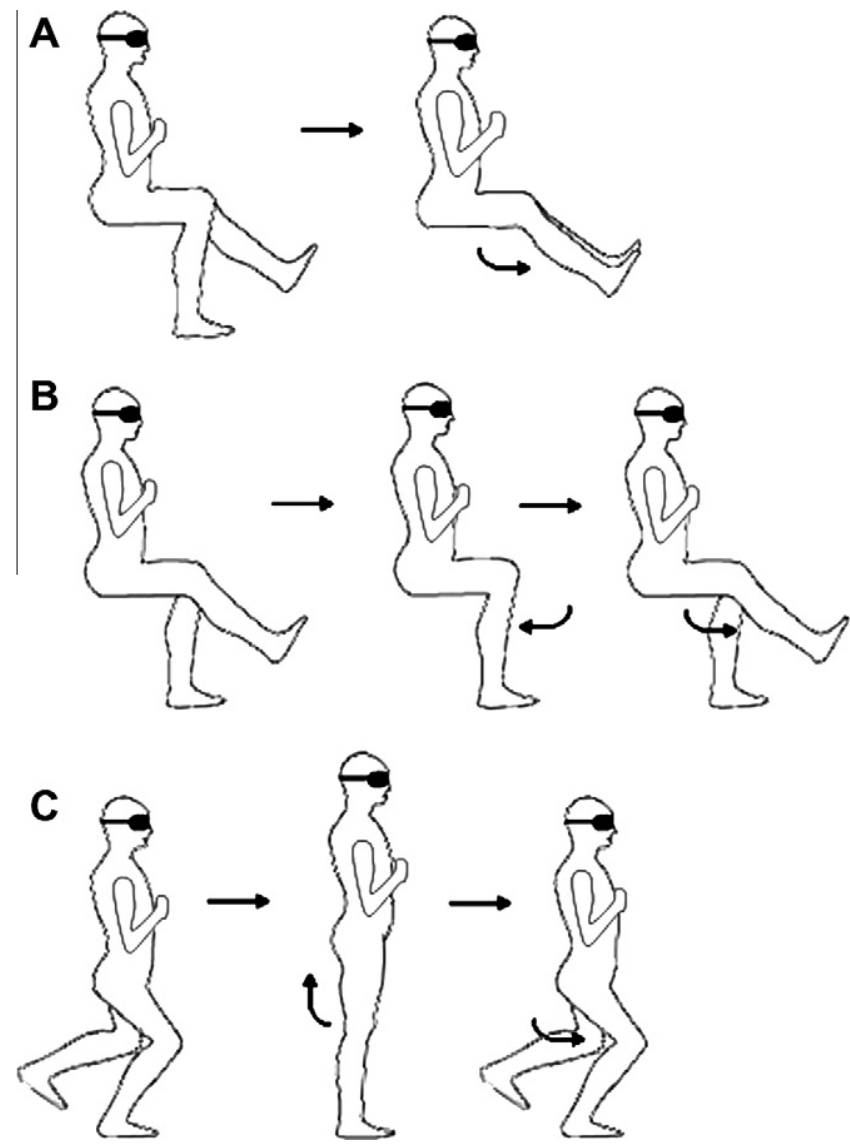

Fig. 1. Illustration of the three proprioception tasks. (A) non-weight bearing position matching; (B) non-weight bearing repositioning; (C) weight bearing repositioning. 
positioned to either $120^{\circ}$ or $150^{\circ}$ using the manual goniometer and the subjects were asked to move their leg towards $90^{\circ}$ of knee extension (relaxed positioning in sitting) and then return their leg to the initial angle as accurately as possible. Finally, for RE$\mathrm{POS}_{\mathrm{WB}}$, the subjects were instructed to stand on their right leg, bend their knee to either $120^{\circ}$ or $150^{\circ}$, which was established using a manual goniometer, straighten their leg into full extension (standing upright) and then return their right knee to the initial angle as accurately as possible.

Participants were allowed to practice each task and then repeated each task twice in a random order. The average of the two repetitions was used for further analysis. For each trial the joint position error was assessed by computing the absolute error and constant error between the start angle and final angle. The constant error was assigned a positive value when the right leg passed the correct angle in the direction of knee extension and negative when in flexion. Additionally the variable error was calculated which provides and indication of the variability of the subject's performance.

\subsubsection{Control measures}

The 10 control subjects performed the same repositioning task in sitting as the main subject group and proprioception errors were measured at baseline, $10 \mathrm{~min}$ after baseline, and $24 \mathrm{~h}$ later. The control group did not perform the eccentric exercise protocol.

\subsection{Statistical analysis}

A one-way repeated-measures ANOVA was used to analyze maximum voluntary knee extension torque, with time as the repeated measure (baseline, immediately post exercise, and $24 \mathrm{~h}$ post exercise). A two-way repeated-measures ANOVA was used to analyze the joint position error for each task, with angle $\left(120^{\circ}\right.$ and $150^{\circ}$ ) and time (baseline, immediately post exercise, and $24 \mathrm{~h}$ post exercise) as repeated measures. For the control group, a two-way repeated-measures ANOVA was used to analyze the joint position error with angle $\left(120^{\circ}\right.$ and $\left.150^{\circ}\right)$ and time as repeated measures (baseline, $10 \mathrm{~min}$ after baseline, and $24 \mathrm{~h}$ post baseline). A three-way repeated-measures ANOVA was also used to compare the absolute error across all three proprioception tasks with time, proprioception task and angle as repeated measures. Significant differences revealed by ANOVA were followed by post hoc Student-Newman-Keuls (SNK) pair-wise comparisons. Results are reported as mean and SD in the text and SE in figures. Statistical significance was set at $P<0.05$.

\section{Results}

Fig. 2 presents the areas of pain reported by the subjects. $41 \%$ of the subjects reported soreness only over the vastus lateralis muscle, $12 \%$ only over vastus medialis, and $47 \%$ an area of soreness over both vasti. Subjects rated their perceived pain intensity as $3.3 \pm 1.9$ (score out of 10) $24 \mathrm{~h}$ post exercise.

\subsection{Maximum voluntary knee extension force}

Maximum voluntary knee extension force was reduced to $77.0 \pm 12.3 \%(P<0.001)$ immediately following the eccentric exercise and remained reduced at $82.8 \pm 16.2 \% 24 \mathrm{~h}$ post exercise compared to baseline measurements $(P<0.001$; Fig. 3$)$.

\subsection{Proprioception tasks}

The absolute joint position error exhibited by the control group in the REPOS ${ }_{\mathrm{N}-\mathrm{WB}}$ task did not change over time (error at baseline: $3.5 \pm 1.5^{\circ} ; 10 \mathrm{~min}$ after baseline: $2.0 \pm 1.8^{\circ} ; 24 \mathrm{~h}$ after baseline:
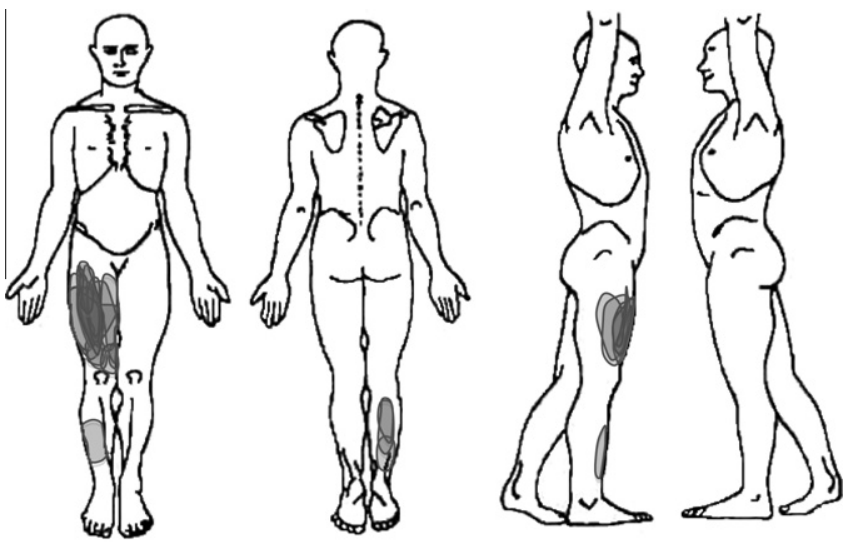

Fig. 2. Area of pain reported by the subjects $24 \mathrm{~h}$ post eccentric exercise. Subjects were asked to draw the area of soreness experienced during their regular activities of daily living (e.g. walking, climbing stairs) in the preceding $24 \mathrm{~h}$.

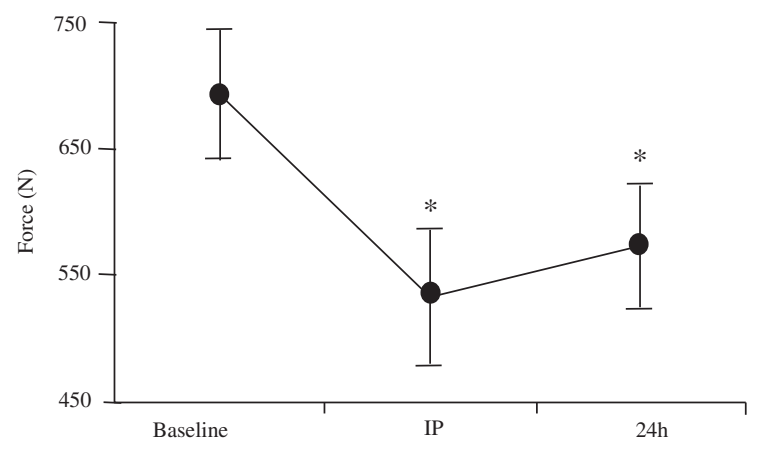

Fig. 3. Mean $\pm \mathrm{SE}$ of the maximum voluntary knee extension force recorded at baseline, immediate post exercise (IP), and $24 \mathrm{~h}$ post exercise $(24 \mathrm{~h}){ }^{*}{ }^{*} P<0.001$ relative to baseline.

$2.9 \pm 1.4^{\circ}$ for $120^{\circ}$, error at baseline: $2.4 \pm 1.2^{\circ}$; $10 \mathrm{~min}$ after baseline: $2.6 \pm 1.6^{\circ} ; 24 \mathrm{~h}$ after baseline: $1.5 \pm 0.9^{\circ}$ for $\left.150^{\circ}\right)$. These results on the control group confirmed the absence of a learning effect.

No difference was observed for the absolute joint error across the three different proprioception tasks at baseline (pooled data for $120^{\circ}$ and $\left.150^{\circ}\right)(P>0.53$; Fig. 4). However, immediately after eccentric exercise, the absolute error observed during the $\operatorname{POS}_{\mathrm{N}-}$ कв task $\left(8.7 \pm 5.9^{\circ}\right)$ was significantly higher than the absolute errors observed in the REPOS $_{\mathrm{N}-\mathrm{WB}}\left(5.1 \pm 2.9^{\circ}\right)$ and REPOS $_{\mathrm{WB}}$ $\left(4.9 \pm 2.7^{\circ} ; P>0.53\right.$; Fig. 4$)$ tasks. Twenty-four hours after exercise, no differences were observed between the absolute errors produced in the three tasks $(P>0.30$; Fig. 4$)$.

\subsection{Position matching task $\left(P_{O S} S_{N-W B}\right)$}

At $120^{\circ}$ of knee extension, the absolute error was greater immediately post exercise $\left(12.3 \pm 5.6^{\circ} ; P<0.001\right)$ compared to baseline $\left(5.8 \pm 2.7^{\circ}\right)$. The absolute error decreased in the period immediately post exercise to $24 \mathrm{~h}(P<0.001)$ but remained greater compared to baseline values $\left(8.1 \pm 4.5^{\circ}, P<0.05\right.$; Fig. $\left.5 \mathrm{~A}\right)$. The subjects moved into a more extended knee position relative to the reference leg, as indicated by the constant error (Fig. 5B). At baseline the constant error was $+6.15 \pm 4.2^{\circ}$ at $120^{\circ}$ and $+3.41 \pm 3.2^{\circ}$ at $150^{\circ}$. Immediately following eccentric exercise, the constant error increased for the $\mathrm{POS}_{\mathrm{N}-\mathrm{WB}}$ task at $120^{\circ}\left(+12.0 \pm 5.8^{\circ}, P<0.05\right)$ and remained increased $24 \mathrm{~h}$ after $\left(+7.73 \pm 5.8^{\circ}, P<0.05\right)$. The degree of the absolute and constant errors were different for the two angles (main effect for angle: $P<0.001$ ); the errors for the task of $\mathrm{POS}_{\mathrm{N}-\mathrm{WB}}$ at $150^{\circ}$ were generally smaller than the errors for $120^{\circ}$ (Fig. 5A, B). No significant changes in positioning accuracy (measured either by the absolute 


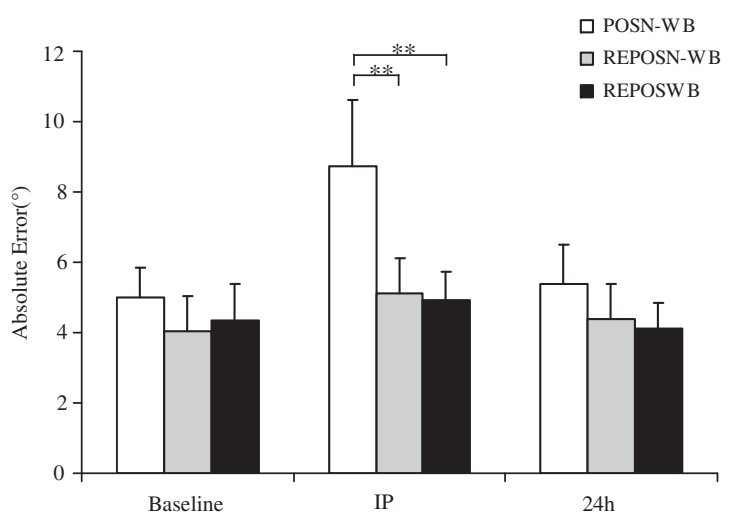

Fig. 4. Mean $\pm S E$ of the absolute joint position error recorded at baseline, immediate post exercise (IP), and $24 \mathrm{~h}$ post exercise $(24 \mathrm{~h}$ ), for the non-weight bearing position matching $\left(\mathrm{POS}_{\mathrm{N}-\mathrm{WB}}\right)$, the non-weight bearing repositioning $\left(\operatorname{REPOS}_{\mathrm{N}-\mathrm{WB}}\right)$ and weight bearing repositioning $\left(\mathrm{REPOS}_{\mathrm{WB}}\right)$ tasks. The values represent the average of the errors obtained at $120^{\circ}$ and $150^{\circ}$ of knee extension. ${ }^{\dagger}$ $P<0.001$.

or constant error) were observed for the position matching task at $150^{\circ}$ of knee extension (Fig. $5 \mathrm{~A}$ and B).

Subjects also became less consistent in their performance after the eccentric exercise. For the task at $120^{\circ}$, the variable error was significantly higher immediately post exercise (5.8 \pm 3.2 , $P<0.001)$ compared to baseline $(2.9 \pm 2.2)$ (Fig. 5C). Although $24 \mathrm{~h}$ after exercise the variable error remained higher $(4.3 \pm 3.1)$ than baseline, no statistical differences were observed (Fig. 5C). For the positioning task at $150^{\circ}$, the consistency of performance was not significantly affected by the exercise protocol (Fig. 5C).

\subsection{Repositioning tasks}

Non-weight bearing task $\left(\operatorname{REPOS}_{\mathrm{N}-\mathrm{WB}}\right)$ - The size of the absolute and constant errors were significantly higher at $120^{\circ}$ than at $150^{\circ}$ (main effect for angle: $P<0.001$ for both). At $120^{\circ}$ of knee exten- sion, the absolute error increased from a baseline value of $4.5 \pm 2.6^{\circ}-5.9 \pm 3.1^{\circ}(P<0.01)$ immediately post exercise and remained greater than baseline $\left(5.3 \pm 2.6^{\circ} ; P<0.05\right) 24$ h post exercise (Fig. 6A). Likewise, the absolute errors at $150^{\circ}$ of knee extension increased from a baseline value of $1.5 \pm 0.9^{\circ}-3.2 \pm 1.9^{\circ}$ $(P<0.01)$ immediately post exercise and remained at $3.1 \pm 2.3^{\circ}$ $(P<0.05) 24 \mathrm{~h}$ post exercise. Consistent with the $\mathrm{POS}_{\mathrm{N}-\mathrm{WB}}$ task, during the REPOS $\mathrm{N}_{\mathrm{N}-\mathrm{B}}$, the subjects also perceived the joint position as more extended (Fig. 6B). When the data of both angles were pooled, the constant error observed immediately after exercise increased from $+3.25 \pm 1.2^{\circ}$ to $+4.5 \pm 1.2^{\circ}(P<0.01)$. After $24 \mathrm{~h}$, the constant error decreased to $+3.8 \pm 1.1^{\circ}$. The consistency of the subject's performance during the REPOS ${ }_{\mathrm{N}-\mathrm{WB}}$ was also affected by the exercise (interaction between time and angle: $P<0.01$; Fig. 6C. At $120^{\circ}$ and immediately after exercise, the variable error was significantly higher $(4.6 \pm 2.3)$ than at baseline $(2.8 \pm 2.6)$ (Fig. 6C). Twenty-four hours after exercise the variable error was similar to baseline values $(2.1 \pm 2.4)$. The variable error was not affected by the exercise protocol at the knee angle of $150^{\circ}$ (Fig. 6C).

Weight bearing task (REPOS ${ }_{W B}$ ) - Fig. 7 shows the joint position errors for the $R E P O S_{W B}$ task at 120 and $150^{\circ}$. Smaller absolute and constant errors were observed at $150^{\circ}$ compared to $120^{\circ}$ of knee extension at all test periods $(P<0.005)$, except for the constant error $24 \mathrm{~h}$ after exercise; Fig. 7A and B. The size of the absolute and constant errors was not affected by eccentric exercise (main effect for time $P>0.23$, for both errors). Although immediately post exercise the subjects appeared less consistence in their performance, no statistical differences was observed when compared to baseline (main effect for time $P>0.12$ ).

\section{Discussion}

Eccentric exercise of the quadriceps impaired proprioception of the knee both immediately after and $24 \mathrm{~h}$ after exercise when tested in a non-weight bearing position. In contrast, eccentric exercise did not affect knee proprioception when tested in a weight bearing position.
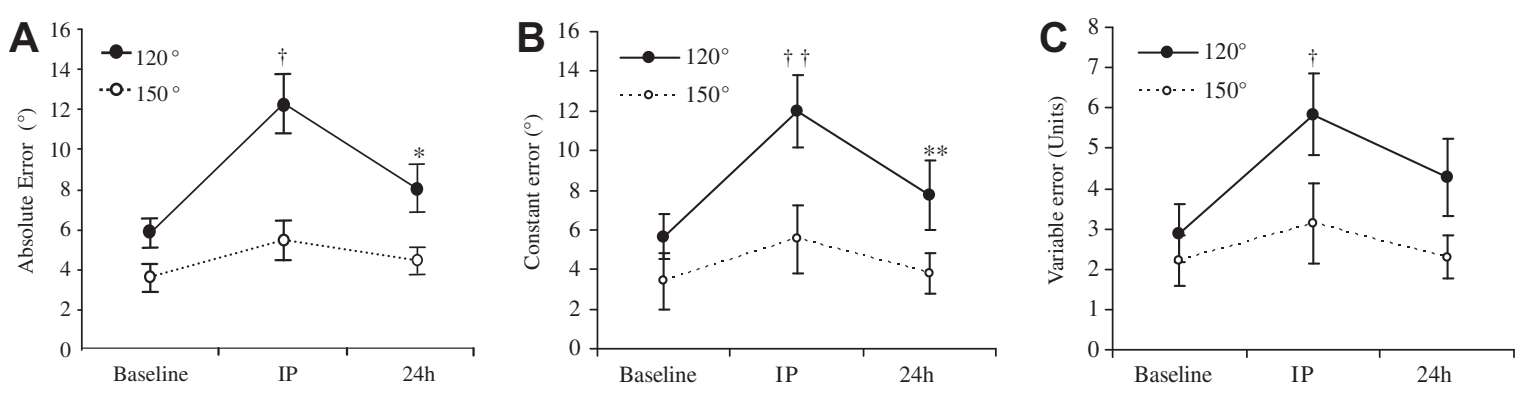

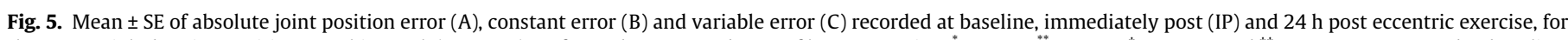

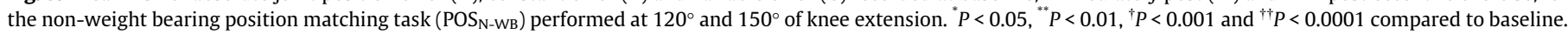
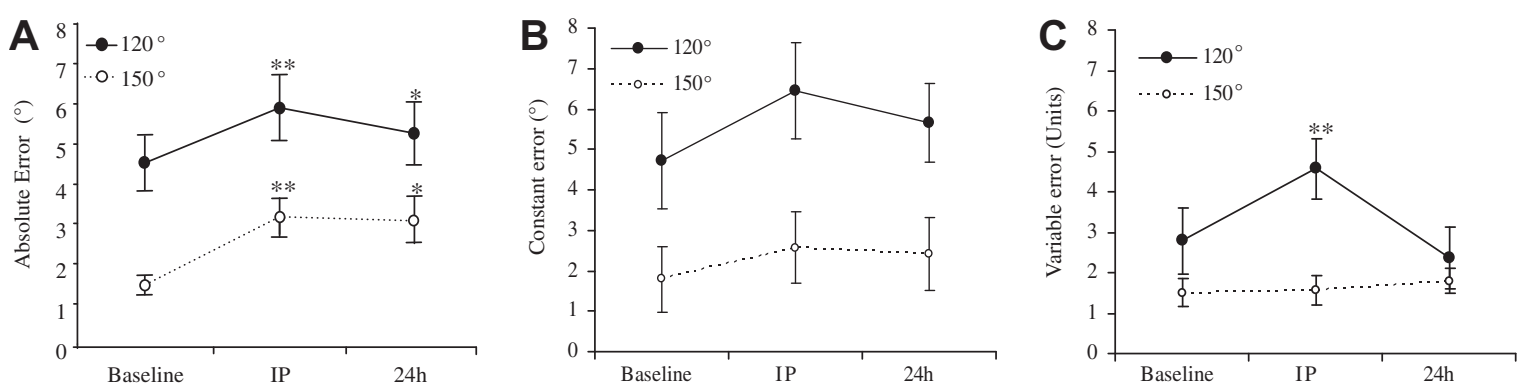

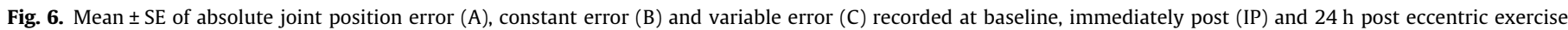

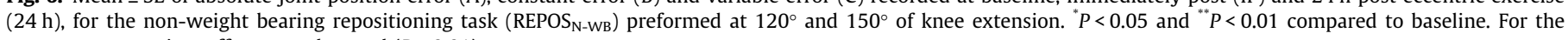
constant error a time effect was observed $(P<0.01)$. 

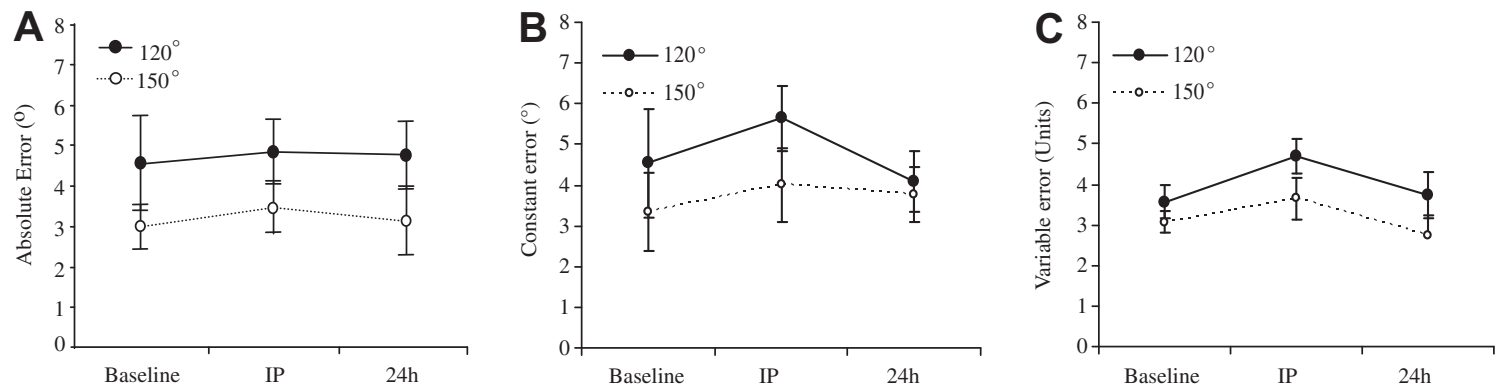

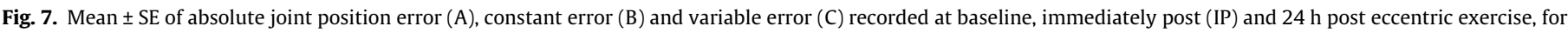

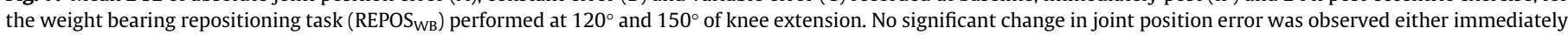
or $24 \mathrm{~h}$ after exercise.

\subsection{Muscle performance}

A reduction in maximal knee extension force was observed both immediately and $24 \mathrm{~h}$ after eccentric exercise which is in agreement with previous studies (Givoni et al., 2007; Hedayatpour et al., 2010). A prolonged force reduction following eccentric exercise is considered the most valid and reliable indirect measure of muscle damage (Clarkson and Hubal, 2002). The reduction in force may be due to disruption of sarcomeres and myofibrils especially in type II muscle fibers (Cheung et al., 2003). However, other alterations induced by unaccustomed eccentric exercise, such as muscle soreness (Jones et al., 1987), shift of the length-tension relationship of the muscle (Howell et al., 1993; Proske and Allen, 2005) and alterations in muscle activation (Dartnall et al., 2009) may contribute to the observed changes in maximal force.

\subsection{Muscle soreness}

The subjects reported soreness in the quadriceps muscle $24 \mathrm{~h}$ post exercise, confirming the presence of DOMS. The average soreness level was $3.3 \pm 1.9$ (score out of 10 ), which is in accordance with similar studies on the quadriceps (Newham et al., 1987). Although the mechanisms leading to DOMS are not clearly established, it has been proposed that the inflammatory process observed in the epimysium of the exercised muscle plays an important role (Clarkson et al., 1992; Crameri et al., 2004). It is suggested that eccentric exercise induces tears within intramuscular connective tissue, which leads to an increase in interstitial inflammatory mediators (Crameri et al., 2007). Consequently, the inflammatory substances activate muscle nociceptors and trigger a pain response (Crameri et al., 2007; Proske and Allen, 2005).

Participants reported soreness more frequently in the area of the vastus lateralis compared to vastus medialis. This difference may be due to greater loading of the vastus lateralis muscle during the eccentric exercise protocol, leading to a greater sensation of DOMS. Furthermore, the vastus lateralis is composed of a higher proportion of type II muscle fibers compared to vastus medialis (Johnson et al., 1973) and type II muscle fibers are more susceptible to exercise-induced disruption (Cheung et al., 2003).

\subsection{Proprioception}

Since the repetition of a task may be associated with learning, the results obtained after eccentric exercise were compared to those obtained by a group of subjects who repeated a proprioception task without the exercise intervention. The consistent repositioning error in the control group confirmed that the observed changes in the study group were not influenced by learning.

Impaired joint position sense was observed both immediately and $24 \mathrm{~h}$ after eccentric exercise particularly for the non-weight bearing tasks at $120^{\circ}$ of knee extension. The subjects matched the predetermined knee position by adopting a more extended position of the tested limb. Similar results have been obtained previously, suggesting that after eccentric exercise the subjects perceived their exercised muscle to be longer than it is (Givoni et al., 2007; Paschalis et al., 2007). This disturbance of proprioception was also accompanied by high variability in task performance.

During voluntary movement, the muscle spindles are considered to be the principal peripheral receptor involved in the sense of limb position and moment (Goodwin et al., 1972). Peripheral signals from stretch receptors in the skin may also contribute to this sense (Edin, 2001). Conversely, the contribution of joint receptors seems to be small (Burke et al., 1988). Thus, one interpretation of the findings could be an abnormal function of the muscle receptors following eccentric exercise. However, animal studies have shown that after intense eccentric exercise the responsiveness of muscle spindles is not disturbed despite extensive muscle damage (Gregory et al., 2004). Moreover, recent studies have shown that immediately after concentric exercise - where no disruption of muscle spindles is expected - the sense of joint position is also impaired (e.g. Walsh et al. 2004). Thus the disturbance in proprioception may be attributed to alterations in central commands rather than to abnormal function of the muscle receptors (Allen et al., 2010).

Disturbance of joint position sense may arise from the altered sense of effort induced by exhaustive exercise. Nevertheless, as explained by Givoni et al. (2007), if the sense of effort generated by supporting the lower limb against the force of gravity contributes to joint position sense, the extra effort necessary to support the fatigued leg would have led the subjects to perceive that their knee was more extended that it was (i.e., the subjects assumed a more flexed knee position). Instead the subjects perceived their knee as more flexed than it was and adopted a more extended knee position (Givoni et al., 2007; Paschalis et al., 2007). The results of the present study also support these observations, which is in disagreement with the effort hypothesis.

Recently, it has been suggested that the effects of exercise on proprioception resides on the operation of an internal forward model (Allen et al., 2007; Bays and Wolpert, 2007). This model estimates the sensory feedback expected for a particular limb position based on past memories and compares it with the actual sensory feedback arising from the fatigued limb. Based on previous experience, the sensory feedback from the fatigued muscle might be greater than anticipated from the motor command. After eccentric exercise, increased muscle activity is required to support the same force level (e.g. lower limb) (Semmler et al., 2007; Turner et al., 2008). Subsequently additional motor unit recruitment can increase alpha-gamma motoneuron co-activation resulting in increased muscle spindle firing (Ploutz et al., 1994). This would lead to a discrepancy between the actual and expected feedback, increasing the size of the position errors (Allen et al., 2007; Givoni et al., 2007). Increased muscle activation is also accompanied by 
enhanced neuronal noise (Berg et al., 2007), which makes the sensory estimation more imprecise and consequently the movement more variable (Bays and Wolpert, 2007). This may partially explain the inconsistency of the subject's performance after exercise.

\subsubsection{Position matching vs. repositioning tasks}

Position matching and repositioning tasks are commonly used by clinicians to assess proprioceptive acuity. Each task reflects different cognitive demands (Goble, 2010). During the repositioning task, the same limb serves to establish both reference and matching locations, which involves a memory component. On the other hand, during the position matching task the reference joint angle is given by the opposing limb. In this task, more interhemisheric communication is required to transfer proprioceptive information (Goble, 2010). The present results showed that at baseline no differences were observed between the joint position errors produced in the non-weight bearing repositioning task and non-weight bearing position matching task. Immediately post exercise however, the joint position errors were greater for the position matching task. This may be due to a discrepancy between the sensory information arising from the non-exercised (reference leg) and exercised leg. During position matching tasks both limbs are compared and their difference is used to position the test limb (Allen et al., 2007; Givoni et al., 2007). As previously mentioned, sensory feedback arising from the exercised leg would be greater after exercise, thus the expected sensory feedback (predicted from the position of the non-exercised leg) would be matched at shorter quadriceps muscle lengths, i.e. at more extended knee positions.

During the non-weight bearing repositioning task, the subject's leg was moved into the predetermined joint position just prior to the test. Thus despite exercise induced alterations in sensory feedback, this short experience of the joint position just prior to the test would have allowed the sensory inflow associated with the central representation of the limb position to be updated. The constant update of the body maps or body schema (Maravita et al., 2003) may have led to a lower discrepancy between the expected and actual sensory feedback from the tested leg, contributing to smaller position errors after exercise in this task.

\subsubsection{Non-weight vs. weight bearing repositioning tasks}

In contrast to the non-weight bearing tasks, proprioceptive acuity was unaffected in a weight bearing task immediately following and $24 \mathrm{~h}$ after eccentric exercise. Even though muscle fatigue and DOMS occurred after the eccentric exercise and therefore sensory feedback arising from the muscles was altered, the correct joint position was maintained during the REPOS ${ }_{\mathrm{WB}}$ task. Additional proprioceptive information may generate from compression through the soles of the foot, contraction of other non-affected muscle groups or from the vestibular system.

\subsubsection{Time course of the changes in proprioception}

During the non-weight bearing position matching task, greater joint position errors occurred immediately post exercise compared to $24 \mathrm{~h}$ later. While immediately after eccentric exercise the effects of muscle fatigue would be the predominant mechanism underlying impaired proprioception, in the following $24 \mathrm{~h}$ DOMS is likely to be the main cause.

The presence of pain may divert the attention level devoted by the subjects to the proprioceptive tasks, disturbing their performance accuracy and consistency. However, recent studies suggest that pain per se is not sufficient to impair proprioception (Weerakkody et al., 2008) or postural control (Corbeil et al., 2004; Hirata et al., 2010) unless the site of pain has a crucial proprioceptive role at the joint involved in the task (Weerakkody et al., 2008). Pain predominately affects motor control via disturbance to sensorimotor processes rather than via cognitive resources related to the per- ception of pain (Corbeil et al., 2004; Hirata et al., 2010; Weerakkody et al., 2008). In the present study the sensation of pain did originate from muscles involved in the positioning tasks, and therefore pain likely contributed to impaired knee proprioception $24 \mathrm{~h}$ after eccentric exercise.

\section{Conclusion}

Eccentric exercise of the quadriceps impairs proprioception of the knee both immediately after and $24 \mathrm{~h}$ post exercise, but only in non-weight bearing tasks.

\section{Acknowledgements}

The authors would like to thank Jens Christian Laursen, Anne Birthe Revsbech, and Anne Flou Kristensen for their help during the data recording.C. Vila-Chã was supported by Fundação para a Ciência e a Tecnologia (FCT) of Portugal. Grant ID - SFRH/BD/31796/2006.

\section{References}

Allen TJ, Ansems GE, Proske U. Effects of muscle conditioning on position sense at the human forearm during loading or fatigue of elbow flexors and the role of the sense of effort. J Physiol 2007;580(Pt. 2):423-34.

Allen TJ, Leung M, Proske U. The effect of fatigue from exercise on human limb position sense. J Physiol 2010;588(Pt 8):1369-77.

Allen TJ, Proske U. Effect of muscle fatigue on the sense of limb position and movement. Exp Brain Res 2006;170(1):30-8.

Armstrong RB. Mechanisms of exercise-induced delayed onset muscular soreness: a brief review. Med Sci Sports Exerc 1984;16(6):529-38.

Bays PM, Wolpert DM. Computational principles of sensorimotor control that minimize uncertainty and variability. J Physiol 2007;578(Pt 2):387-96.

Berg RW, Alaburda A, Hounsgaard J. Balanced inhibition and excitation drive spike activity in spinal half-centers. Science 2007;315(5810):390-3.

Brockett C, Warren N, Gregory JE, Morgan DL, Proske U. A comparison of the effects of concentric versus eccentric exercise on force and position sense at the human elbow joint. Brain Res 1997;771(2):251-8.

Burke D, Gandevia SC, Macefield G. Responses to passive movement of receptors in joint, skin and muscle of the human hand. J Physiol 1988;402:347-61.

Clarkson PM, Hubal MJ. Exercise-induced muscle damage in humans. Am J Phys Med Rehabil 2002;81(Suppl 11):S52-69.

Clarkson PM, Nosaka K, Braun B. Muscle function after exercise-induced muscle damage and rapid adaptation. Med Sci Sports Exerc 1992;24(5):512-20.

Corbeil P, Blouin JS, Teasdale N. Effects of intensity and locus of painful stimulation on postural stability. Pain 2004;108(1-2):43-50.

Crameri RM, Langberg H, Magnusson P, Jensen CH, Schroder HD, Olesen JL, et al Changes in satellite cells in human skeletal muscle after a single bout of high intensity exercise. J Physiol 2004;558(Pt 1):333-40.

Crameri RM, Aagaard P, Qvortrup K, Langberg H, Olesen J, Kjaer M. Myofibre damage in human skeletal muscle: effects of electrical stimulation versus voluntary contraction. J Physiol 2007;583(Pt 1):365-80.

Dartnall TJ, Rogasch NC, Nordstrom MA, Semmler JG. Eccentric muscle damage has variable effects on motor unit recruitment thresholds and discharge patterns in elbow flexor muscles. J Neurophysiol 2009;102(1):413-23.

Edin B. Cutaneous afferents provide information about knee joint movements in humans. J Physiol 2001;531(Pt 1):289-97.

Givoni NJ, Pham T, Allen TJ, Proske U. The effect of quadriceps muscle fatigue on position matching at the knee. J Physiol 2007;584(Pt 1):111-9.

Goble DJ. Proprioceptive acuity assessment via joint position matching: from basic science to general practice. Phys Ther 2010;90(8):1176-84.

Goodwin GM, McCloskey DI, Matthews PB. Proprioceptive illusions induced by muscle vibration: contribution by muscle spindles to perception? Science 1972;175(28):1382-4.

Granata KP, Marras WS, Davis KG. Variation in spinal load and trunk dynamics during repeated lifting exertions. Clin Biomech (Bristol, Avon) 1999;14(6):367-75.

Gregory JE, Morgan DL, Proske U. Responses of muscle spindles following a series of eccentric contractions. Exp Brain Res 2004;157(2):234-40.

Hedayatpour N, Falla D, Arendt-Nielsen L, Farina D. Effect of delayed-onset muscle soreness on muscle recovery after a fatiguing isometric contraction. Scand J Med Sci Sports 2010;20(1):145-53.

Hirata RP, Arendt-Nielsen L, Graven-Nielsen T. Experimental calf muscle pain attenuates the postural stability during quiet stance and perturbation. Clin Biomech (Bristol, Avon) 2010;25(9):931-7.

Howell JN, Chleboun G, Conatser R. Muscle stiffness, strength loss, swelling and soreness following exercise-induced injury in humans. J Physiol 1993;464:183-96

Johnson MA, Polgar J, Weightman D, Appleton D. Data on the distribution of fibre types in thirty-six human muscles. An autopsy study. J Neurol Sci 1973;18(1):111-29.

Jones DA, Newham DJ, Clarkson PM. Skeletal muscle stiffness and pain following eccentric exercise of the elbow flexors. Pain 1987;30(2):233-42. 
Kelly AK. Anterior cruciate ligament injury prevention. Curr Sports Med Rep 2008;7(5):255-62.

Lephart SM, Fu FH. Proprioception and neuromuscular control in joint stability: Human Kinetics 2000.

Maravita A, Spence C, Driver J. Multisensory integration and the body schema: close to hand and within reach. Curr Biol 2003;13(13):R531-9.

Newham DJ, Jones DA, Clarkson PM. Repeated high-force eccentric exercise: effects on muscle pain and damage. J Appl Physiol 1987;63(4):1381-6.

Paschalis V, Nikolaidis MG, Giakas G, Jamurtas AZ, Pappas A, Koutedakis Y. The effect of eccentric exercise on position sense and joint reaction angle of the lower limbs. Muscle Nerve 2007;35(4):496-503.

Ploutz LL, Tesch PA, Biro RL, Dudley GA. Effect of resistance training on muscle use during exercise. J Appl Physiol 1994;76(4):1675-81.

Proske U, Allen TJ. Damage to skeletal muscle from eccentric exercise. Exerc Sport Sci Rev 2005;33(2):98-104.

Proske U, Gandevia SC. The kinaesthetic senses. J Physiol 2009;587(Pt 17):4139-46.

Proske U, Gregory JE, Morgan DL, Percival P, Weerakkody NS, Canny BJ. Force matching errors following eccentric exercise. Hum Mov Sci 2004;23(34):365-78.

Proske U, Morgan DL. Muscle damage from eccentric exercise: mechanism, mechanical signs, adaptation and clinical applications. J Physiol 2001;537(Pt 2):333-45.

Proske U, Weerakkody NS, Percival P, Morgan DL, Gregory JE, Canny BJ. Forcematching errors after eccentric exercise attributed to muscle soreness. Clin Exp Pharmacol Physiol 2003;30(8):576-9.

Sanna G, O'Connor KM. Fatigue-related changes in stance leg mechanics during sidestep cutting maneuvers. Clin Biomech (Bristol, Avon) 2008;23(7):946-54.

Saxton JM, Clarkson PM, James R, Miles M, Westerfer M, Clark S, et al Neuromuscular dysfunction following eccentric exercise. Med Sci Sports Exerc 1995;27(8):1185-93.

Semmler JG, Tucker KJ, Allen TJ, Proske U. Eccentric exercise increases EMG amplitude and force fluctuations during submaximal contractions of elbow flexor muscles. J Appl Physiol 2007;103(3):979-89.

Turner TS, Tucker KJ, Rogasch NC, Semmler JG. Impaired neuromuscular function during isometric, shortening, and lengthening contractions after exerciseinduced damage to elbow flexor muscles. J Appl Physiol 2008;105(2):502-9.

Walsh LD, Allen TJ, Gandevia SC, Proske U. Effect of eccentric exercise on position sense at the human forearm in different postures. J Appl Physiol 2006;100(4):1109-16.

Walsh LD, Hesse CW, Morgan DL, Proske U. Human forearm position sense after fatigue of elbow flexor muscles. J Physiol 2004;558(Pt 2):705-15.

Weerakkody NS, Blouin JS, Taylor JL, Gandevia SC. Local subcutaneous and muscle pain impairs detection of passive movements at the human thumb. J Physiol 2008;586(13):3183-93.

Winter JA, Allen TJ, Proske U. Muscle spindle signals combine with the sense of effort to indicate limb position. J Physiol 2005;568(Pt 3):1035-46.

Yu JG, Thornell LE. Desmin and actin alterations in human muscles affected by delayed onset muscle soreness: a high resolution immunocytochemical study. Histochem Cell Biol 2002;118(2):171-9

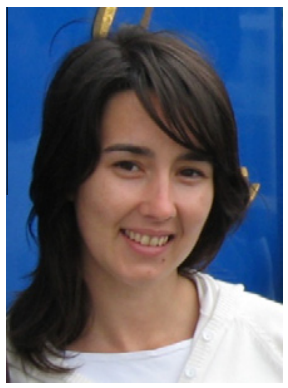

Carolina Vila-Chã received a B.Sc. and M.Sc. in Sports Science from the University of Porto, Portugal. Since 2000, she has been assistant professor at the Department of Sports Science of the Polytechnic Institute of Bragança, Portugal. In 2007 she received a grant from the Fundação para a Ciência e a Tecnologia (FCT) of Portugal and started her PhD in Biomedical Engineering at the University of Porto; since then she has been a guest researcher at the Center for SensoryMotor Interaction, Aalborg University, Denmark. Her research is focused on the assessment of neuromuscular adaptations to training by means of advanced EMG techniques. Her scientific interests also include exploration of neuromuscular alterations induced by muscle fatigue and delayed muscle onset soreness and their impact on motor control.

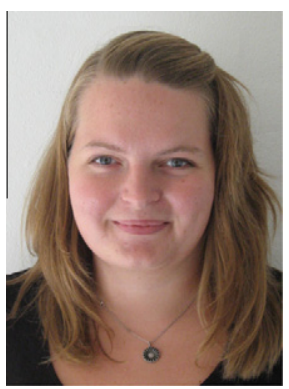

Simone Riis is a Masters candidate in Medicine with Industrial Specialization, Aalborg University, Denmark.

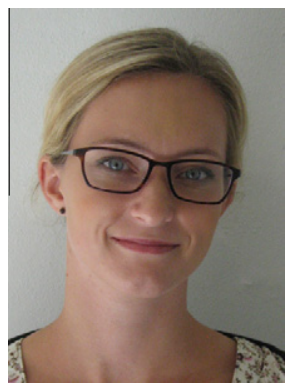

Ditte Lund is a Masters candidate in Medicine with Industrial Specialization, Aalborg University, Denmark.

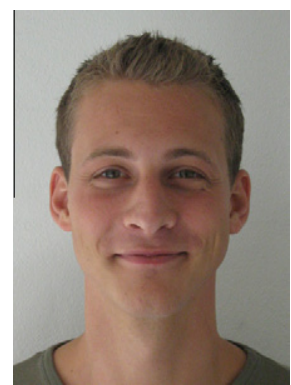

Anders Møller is a Masters candidate in Medicine with Industrial Specialization, Aalborg University, Denmark.

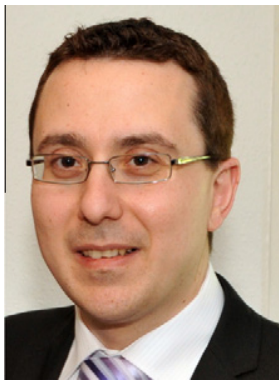

Dario Farina obtained the MSc degree in Electronics Engineering from Politecnico di Torino, Torino, Italy, in 1998, and the PhD degree in Automatic Control and Computer Science and in Electronics and Communications Engineering from the Ecole Centrale de Nantes, Nantes, France, and Politecnico di Torino, respectively, in 2002. In 2002-2004 he has been Research Assistant Professor at Politecnico di Torino and in 2004-2008 Associate Professor in Biomedical Engineering at Aalborg University, Aalborg, Denmark. From 2008 to 2010 he has been Full Professor in Motor Control and Biomedical Signal Processing at Aalborg University and in 2010 he has been appointed Full Professor and Founding Chair of the Department of Neurorehabilitation Engineering at the Georg-August University of Göttingen, Göttingen, Germany, within the Bernstein Center for Computational Neuroscience. Since 2010 he is the Vice-President of the International Society of Electrophysiology and Kinesiology (ISEK). He is the recipient of the 2010 IEEE Engineering in Medicine and Biology Society Early Career Achievement Award. He is an Associate Editor of IEEE Transactions on Biomedical Engineering and of Medical \& Biological Engineering \& Computing and member of the Editorial Boards of the Journal of Electromyography and Kinesiology and of the Journal of Neuroscience Methods. His research focuses on biomedical signal processing and modeling, neurorehabilitation, and neural control of movement. Within these areas, he has (co)-authored approximately 200 papers in peer-reviewed Journals and about 300 among conference papers/abstracts, book chapters and encyclopedia contributions.

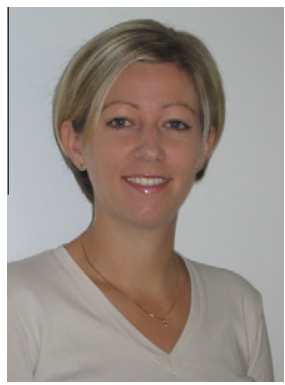

Deborah Falla received her $\mathrm{PhD}$ from The University of Queensland, Australia in 2003. In 2005 she was awarded Fellowships from the International Association for the Study of Pain and the National Health and Medical Research Council of Australia to undertake postdoctoral research at the Center for Sensory-Motor Interaction, Aalborg University, Denmark. Since 2008 she is Associate Professor in the Faculty in Medicine, Department of Health Science and Technology, Aalborg University, Denmark. Her research focus involves the integration of neurophysiological and clinical research to evaluate neuromuscular control of the spine in people with chronic pain. Her research interests also include motor skill learning and training for musculoskeletal pain disorders. In this field she has published over 50 papers in peer-reviewed Journals, more than 100 conference papers/abstracts and received the Delsys Prize for Electromyography Innovation in 2004. She has given over 60 invited lectures and has provided professional continuing education courses on the management of neck pain to health practitioners in 18 countries. She is co-author of the book entitled "Whiplash, Headache and Neck Pain: Research Based Directions for Physical Therapies" published by Elsevier and is Associate Editor of the journal Manual Therapy. Since 2010 she is a Council member of the International Society of Electrophysiology and Kinesiology (ISEK) 